\title{
Paclitaxel and baccatin III production induced by methyl jasmonate in free and immobilized cells of Taxus baccata
}

\author{
M. BONFILL ${ }^{1}$, S. BENTEBIBEL ${ }^{1}$, E. MOYANO ${ }^{2}$, J. PALAZÓN $^{1}$, R.M $^{\text {a }}$ CUSIDÓ $^{1 *}$, R. EIBL $^{3}$ \\ and M.T. PIÑOL ${ }^{1}$ \\ Laboratorio de Fisiologia Vegetal, Facultad de Farmacia, Universidad de Barcelona, \\ Avda. Diagonal 643, E-08028 Barcelona, Spain ${ }^{1}$ \\ Departament de Ciències Experimentals i de Salut, Universitat Pompeu Fabra, E-08003 Barcelona, Spain ${ }^{2}$ \\ Hochschule Wädenswill, CH-8820 Wädenswill, Switzerland ${ }^{3}$
}

\begin{abstract}
The effects of 100 and $200 \mu \mathrm{M}$ methyl jasmonate (MJA) on cell proliferation and paclitaxel and baccatin III production were investigated in free and alginate immobilized cells of Taxus baccata growing in a selected product formation culture medium. The greatest accumulation of paclitaxel $\left(13.20 \mathrm{mg} \mathrm{dm}^{-3}\right)$ and baccatin III $\left(4.62 \mathrm{mg} \mathrm{dm}^{-3}\right) \mathrm{occurred}$ when $100 \mu \mathrm{M}$ MJA was added to the culture medium of cells entrapped using a 1.5 and $2.5 \%$ alginate solution. The effects of different treatments on the viability of cultured cells and their capacity to excrete both taxanes into the surrounding medium were considered.
\end{abstract}

Additional key words: alginate entrapped cells, cell cultures, elicitation, taxanes, yew.

\section{Introduction}

Paclitaxel (taxol; NSC-125973), a secondary metabolite of the Taxus species, has been recognized as the best anticancer drug to have emerged in the past 20 years. However, due to the difficulties in obtaining this compound from yew trees the clinical use of paclitaxel has been limited, which has motivated the development of alternative production sources. An alternative approach for obtaining paclitaxel is semisynthesis from more abundant taxanes, for example, via the conversion of baccatine III isolated from the needles of yew trees (Hezari et al. 1997). Another alternative for the production of paclitaxel and related taxanes is the use of cell cultures. Total synthesis is not commercially viable because of the high cost of the process (Nicolau et al. 1994).

The accumulation of paclitaxel and related taxanes in Taxus plants is thought to be a biological response to specific external stimuli (Yukimune et al. 1996, Yu et al. 2005). Exogenously applied methyl jasmonate enhances production of secondary metabolites in a variety of plant

species, and in particular it is the most effective chemical for eliciting taxane production in various Taxus suspension cultures (Yukimune et al. 1996, Ketchum et al. 1999, Cusidó et al. 2002, Bonfill et al. 2003, Ketchum et al. 2003, Tabata 2004). Moreover, the development of Taxus cell cultures capable of producing significant amounts of paclitaxel and related taxanes, and inducible by elicitation with methyl jasmonate provides an excellent tool to improve our understanding of how the biosynthesis of these compounds is regulated in vitro. Seki et al. (1997) reported an immobilized Taxus cell system but did not experiment with elicitation, and in our recent work, also using a T. baccata cell line (Bentebibel et al. 2005), the main proposal was to study the effects of immobilization and scale-up on the production of both taxanes. The purpose of this work is to study the effect of methyl jasmonate, concentration and cell immobilization on cell viability, growth rate and production of paclitaxel and its synthetically useful progenitor baccatin III.

Received 16 August 2005, accepted 20 July 2006.

Abbreviations: B5 - Gamborg's B5 medium; BAP - benzylaminopurine; MJA - methyl jasmonate; NAA - naphthaleneacetic acid. Acknowledgements: This research has been partly supported by two grants from the Spanish CICYT (BIO2002-02328 and BIO2002-03614).

* Corresponding author; fax: (+43) 93 4029043, e-mail: rcusido@ub.edu 


\section{Materials and methods}

Taxus baccata L. cell suspension was maintained in $175-\mathrm{cm}^{3}$ flasks (Sigma, St. Louis, MO, USA) in the dark at $25 \pm 0.2{ }^{\circ} \mathrm{C}$ and $100 \pm 1 \mathrm{rpm}$ in a shaker-incubator (Adolf Kühner AG, Basel, Schwitzerland). Every $10-12 \mathrm{~d} 1 \pm 0.2 \mathrm{~g}$ of cells were used as inoculum in $10 \mathrm{~cm}^{3}$ of Gamborg's B5 medium (B5; Gamborg et al. 1968 ) with $0.5 \%$ sucrose $+0.5 \%$ fructose, $2 \mathrm{mg} \mathrm{dm}^{-3}$ of naphthaleneacetic acid (NAA) and $0.1 \mathrm{mg} \mathrm{dm}^{-3}$ of benzylaminopurine (BAP), which has previously been demonstrated as optimum for the cell suspension growth (Palazón et al. 2003). All flasks were capped with Magenta B-Caps (Sigma).

Sodium alginate, at the concentrations 1.5, 2 and $2.5 \%$, was used for immobilization of cells, using the technique described by Gilleta et al. (2000). Considering that the paclitaxel production in Taxus cell cultures takes place mainly when the linear growth phase has finished and the culture is at the beginning of its stationary growth phase (Srinivasan et al. 1996, Fett-Neto and DiCosmo 1997, Cusidó et al. 2002), $2 \pm 0.2 \mathrm{~g}$ fresh mass of free cells grown for $13 \mathrm{~d}$ in the growth medium, were mixed with 10 of a sterile solution of sodium alginate of high viscosity (Sigma) and then dropped into 100 of a $2.5 \%$ sterile calcium chloride solution to form biocatalyst beads by ionotropic gelation of alginate. The beads were transferred to $10 \mathrm{~cm}^{3}$ of B5 medium with $3 \%$ sucrose, $2 \mathrm{mg} \mathrm{dm}^{-3}$ of Picloram and $0.1 \mathrm{mg} \mathrm{dm}^{-3}$ of kinetin, which had previously been selected as optimum for both paclitaxel and baccatin III yield (Palazón et al. 2003), and they were then submitted to the same culture conditions as free cells. Cultures of free cells were performed with cells in their stationary growth phase growing in the product formation medium supplemented with 100 or $200 \mu \mathrm{M}$ methyl jasmonate (MJA) or without the elicitor

\section{Results and discussion}

Effects of methyl jasmonate on free cultured cells: The time courses of growth of T. baccata free cells in their initial stationary growth phase growing in a selected product formation medium with 100 or $200 \mu \mathrm{M}$ MJA or without the elicitor (control) are compared (Fig. 1). Although the increase in cell biomass was higher in elicited than control cultures, in neither concentration were these differences notable. Moreover, in all cases the biomass increased slightly, without the typical linear growth phase usually obtained during the growth course of a cell suspension culture. When the concentration of MJA added to the production medium was $100 \mu \mathrm{M}$, the cell biomass reached a maximum of $9 \mathrm{~g} \mathrm{dm}^{-3}$ on day 24 . The same maximum biomass was reached with $200 \mu \mathrm{M}$ but on day 16 . In both cases this represented an increase of $5 \mathrm{~g}$ in relation to the initial biomass. These relatively small increases of biomass indicated that the cells cultured in presence of MJA remained in stationary (control) at day 0 of the culture cycle (Yukimune et al. 1996). Equal volumes of ethanol were added to all cultures. All compounds were sterilized by filtering through $0.22 \mu \mathrm{m}$ sterile filters (Millipore, Billerica, USA). For analysis, five flasks from each treatment were harvested at $6 \mathrm{~h}$ after subculturing (day 0) and subsequently at days $8,16,24$ and 38 .

The bead samples were removed from the immobilized cell cultures. The calcium alginate support was dissolved by adding $20 \mathrm{~cm}^{3}$ of EDTA-phosphate solution ( 0.1 and $0.2 \mathrm{M}$, respectively) and stirring for $30 \mathrm{~min}$. The liberated cells and free cultured cells were filtered on preweighed Whatman filters No. 42 and fresh mass was determined. They were then lyophilised to obtain dry mass and analysed to determine their content of paclitaxel and baccatin III. Cell viability was estimated with fluorescein diacetate (FDA) staining as described by Duncan and Widholm (1990).

Taxanes were extracted from lyophilised cells and the culture medium as described by Cusidó et al. (1999). Quantification of paclitaxel and baccatin III was performed according to Grothaus et al. (1995) using an indirect competitive enzyme immunoassay (CIEIA). In order to determine the accuracy of this method a previous quantification of taxanes in cell extracts from shake flask cultures of free cells grown in control conditions was performed by CIEIA and high performance liquid chromatography (HPLC) (Bentebibel et al. 2005). HPLC analyses were carried out as described in Bonfill et al. (2003). Paclitaxel and baccatin III-protein, coating antigen, anti-paclitaxel and anti-baccatin III monoclonal antibodies and the corresponding standards were obtained from the Hawaii-Biotechnology Group (Aiea, Hawaii, USA).

growth phase throughout the culture period. This was satisfactory for our aims since, as previously mentioned, in Taxus cell cultures the biosynthesis of paclitaxel and baccatin III mainly takes place when the culture is in its stationary growth phase. As cells in this state are characterised by limited rates of cell division, it has been considered that products from primary metabolism are accumulated and/or they are available for secondary metabolite production (Hall et al. 1988). It is of interest that the viability percentage of cultured cells was always more than $75 \%$ (data not shown), indicating that the low growth rate observed was not a consequence of cell lysis.

Jasmonates inhibit growth mainly by the disruption of cortical microtubules (Koda et al. 1996), a phenomenon ubiquitous in plants. However, under conditions of this work, the biomass was affected to a greater degree by the culture medium composition than by the MJA concentration. Our findings are consistent with the 
previous results of Ketchum et al. (1999), who examined the effect of MJA on paclitaxel accumulation in three cell lines of $T$. canadensis over a 2-year period, and postulated that, within a cell line, there was no difference in cell growth between elicited and nonelicited cell cultures.

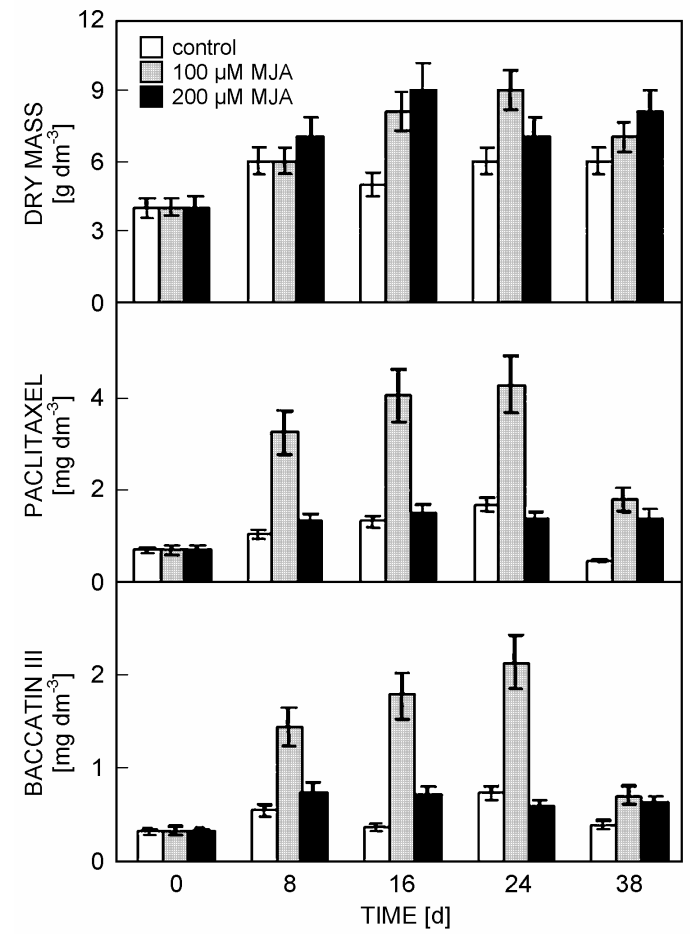

Fig. 1. Time courses of dry mass and total (cell-associated and extracellular) paclitaxel and baccatin III contents in T. baccata free cells cultured for $38 \mathrm{~d}$ in product formation medium with 100 or $200 \mu \mathrm{M}$ methyl jasmonate or without the elicitor (control). In all cases, the inoculum consisted of $100 \mathrm{~g}$ of cells in stationary growth state per $\mathrm{dm}^{-3}$ of medium. Data represent average values from 5 separate experiments \pm SE.

In contrast to the minimal effect of MJA elicitation on cell growth, considerable differences in total (cellassociate + extracellular) paclitaxel and baccatin III content were observed in the cells grown in medium supplemented with 100 or $200 \mu \mathrm{M}$ MJA. The maximum total paclitaxel content was $4.25 \mathrm{mg} \mathrm{dm}^{-3}$ on day 24 in the presence of the $100 \mu \mathrm{M}$ MJA, though that observed on day $16\left(4.02 \mathrm{mg} \mathrm{dm}^{-3}\right)$ was almost as high. These quantities of paclitaxel were about 2.7-fold greater than the maximum achieved in the treatment with $200 \mu \mathrm{M}$ MJA (1.49 $\mathrm{mg} \mathrm{dm}^{-3}$ on day 16$)$

The maximum total baccatin III content was $2.4 \mathrm{mg} \mathrm{dm}^{-3}$ on day 24 in presence of $100 \mu \mathrm{M}$ MJA, being $0.75 \mathrm{mg} \mathrm{dm}^{-3}$ in presence of $200 \mu \mathrm{M}$ MJA. Compared to the maximum total content of this taxane in the control $\left(0.73 \mathrm{mg} \mathrm{dm}^{-3}\right.$ on day 24$)$, it seems evident that only the $100 \mu \mathrm{M}$ MJA clearly increased the yield of baccatin III. As the cell growth during the culture period considered was similar, it seems clear that the stimulating effect of $200 \mu \mathrm{M}$ MJA on the synthesis and/or activation of certain enzymes involved in the formation of both taxanes was considerably lower than that of $100 \mu \mathrm{M}$ MJA, which supports the previous observation (Yukimune et al. 1996) that the MJA concentration used is critical for the maximum effect on Taxus cell cultures. In a previous work (Ketchum et al. 1999), it has been demonstrated that the greatest accumulation of paclitaxel occurs when MJA is added to Taxus cell cultures at a final concentration of $200 \mu \mathrm{M}$. This difference may be partly attributable to the fact that these authors cultured a different species, $T$. canadensis, or that they analysed only the extracellular taxanes present in the cell-free medium, whereas we assayed the total content (cellassociate + extracellular) of paclitaxel and baccatin III.

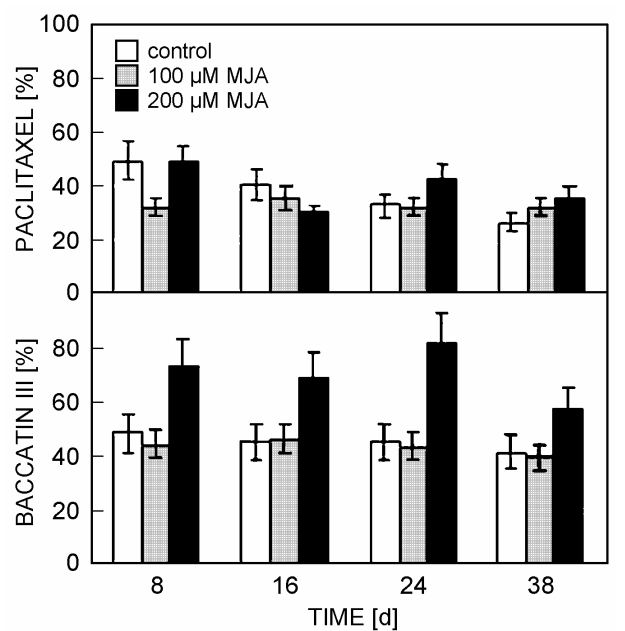

Fig. 2. Excretion percentage of paclitaxel and baccatin III into the liquid medium by $T$. baccata free cells cultured for $38 \mathrm{~d}$ in $175 \mathrm{~cm}^{3}$ shake flasks containing $10 \mathrm{~cm}^{3}$ of product formation medium with 100 or $200 \mu \mathrm{M}$ methyl jasmonate or without the elicitor (control). In all cases, the inoculum consisted of $100 \mathrm{~g}$ of cells in stationary growth state per $\mathrm{dm}^{-3}$ of medium. Data represent average values from 5 separate experiments \pm SE.

Furthermore, the amounts of paclitaxel and baccatin III secreted from day 8 to day 38 (Fig. 2) into the culture medium by productive cells (i.e. the extracellular content) were affected by the treatment with 100 or $200 \mu \mathrm{M}$ MJA. Compared to the excretion percentage averages in the untreated control $(37 \%$ for paclitaxel and $44 \%$ for baccatin III), those of the cultures supplemented with $100 \mu \mathrm{M}$ MJA were practically the same for both taxanes, while when the elicitor concentration was increased to $200 \mu \mathrm{M}$ the excretion percentage was slightly lower (32\%) for paclitaxel but considerably higher $(70 \%)$ for baccatin III. Currently, the reason why some taxanes are accumulated and others are excreted by cells is unknown. However, the capacity of Taxus cells to excrete accumulated taxanes into the culture medium is an important factor since this accumulation may limit biosynthesis (Seki et al. 1997), possibly by means of a feedback inhibition mechanism. 
Effects of MJA on immobilized cultured cells: The biomass production of cells within calcium alginate beads, also in their stationary growth phase, determined at days 8, 16, 24 and 38 of the culture (Fig. 3), was increased by $100 \mu \mathrm{M}$ MJA regardless of the concentration of the alginate solution used for cell immobilization. The maximum biomass formed within the beads prepared with $1.5,2$ and $2.5 \%$ alginate was, in presence of $100 \mu \mathrm{M}$ MJA, only 4, 4, and $5 \mathrm{~g}$ greater, respectively, than the initial biomass of $4 \mathrm{~g}(\mathrm{~d} . \mathrm{m}.) \mathrm{dm}^{-3}$, and in presence of $200 \mu \mathrm{M}$ MJA the corresponding values were only 2, 3, and $3 \mathrm{~g}$ greater. As observed for free cultured cells, these relatively small increases of biomass after a culture period of $38 \mathrm{~d}$ indicated that the immobilized cells also remained in stationary growth phase during the considered period. Villegas et al. (1999) and Gilleta et al. (2000) demonstrated that cells of Eschscholtzia californica and Nicotiana tabacum immobilized in alginate calcium beads show a growth rate that is not as high as that of free growing cells, but considerably greater than the growth rate obtained for our T. baccata immobilized cells. These differences may be partly attributable to the fact that these authors, apart from using species with a much faster growth rate than that of Taxus, immobilized the cells in their linear growth phase. Furthermore, they did not use culture media that

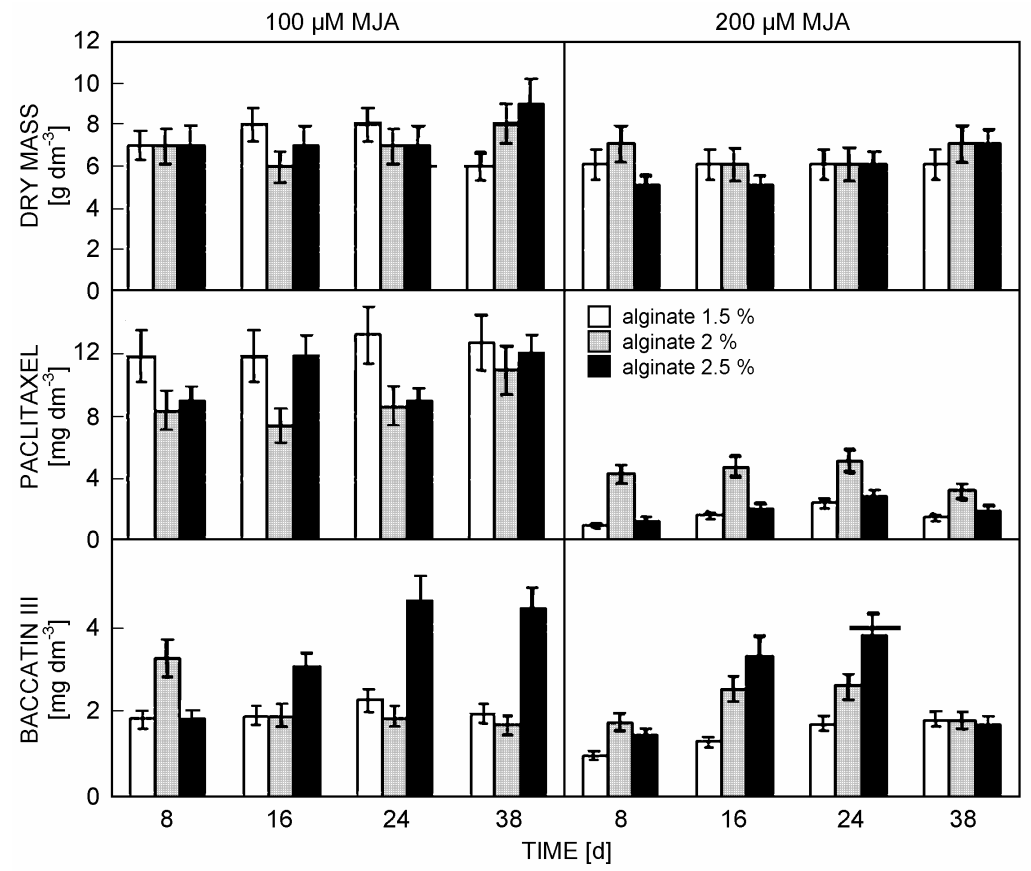

Fig. 3. Time courses of biomass accumulation and total (cell-associated + extracellular) paclitaxel and baccatin III yield by T. baccata alginate-entrapped cells using $1,1.5$ and $2.5 \%$ alginate solution and medium with 100 or $200 \mu \mathrm{M}$ methyl jasmonate. In all cases, the inoculum consisted of $100 \mathrm{~g}$ of cells in stationary growth state per $\mathrm{dm}^{-3}$ of medium. Data represent average values from 5 separate experiments $\pm \mathrm{SE}$.

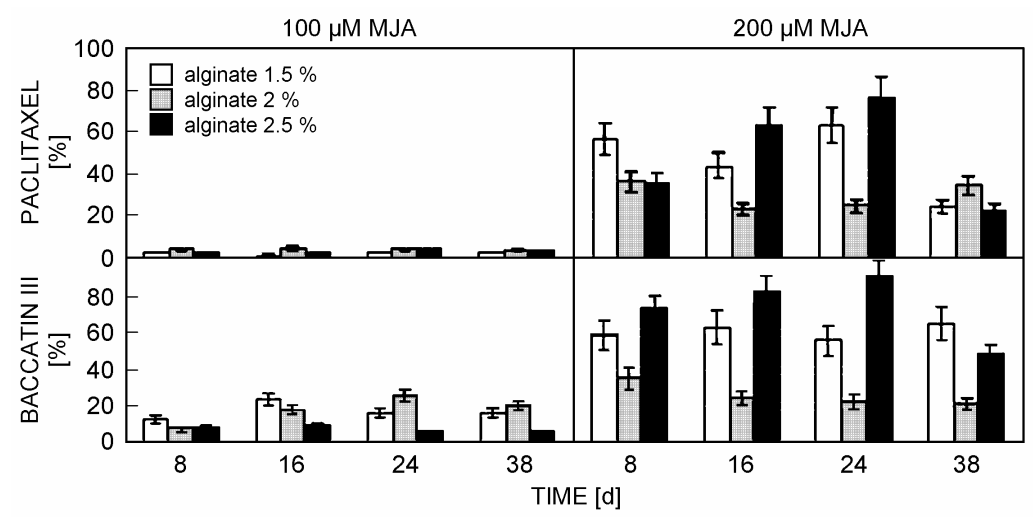

Fig. 4. Excretion percentage of paclitaxel and baccatin III into the liquid medium by $T$. baccata alginate-entrapped cells using $1,1.5$ and $2.5 \%$ alginate solution with 100 or $200 \mu \mathrm{M}$ methyl jasmonate. In all cases, the inoculum consisted of $100 \mathrm{~g}$ of cells in stationary growth state per $\mathrm{dm}^{3}$ of medium. Data represent average values from 5 separate experiments $\pm \mathrm{SE}$. 
specifically stimulate the production of the secondary metabolites.

Cell immobilization noticeably stimulated the production of both taxanes, although there were differences according to the alginate concentration used for cell immobilization and the presence of 100 or $200 \mu \mathrm{M}$ MJA in the culture medium. In presence of $100 \mu \mathrm{M}$ MJA, the maximum accumulation of paclitaxel $\left(13.20 \mathrm{mg} \mathrm{dm}^{-3}\right)$ was achieved at day 24 when using the $1.5 \%$ alginate, while the maximum accumulation at higher alginate concentrations of 2 and $2.5 \%$, was achieved at the end of the culture ( 10.85 and $11.90 \mathrm{mg} \mathrm{dm}^{-3}$, respectively), and was clearly lower. However, the maximum accumulation of baccatin III (4.62 $\mathrm{mg} \mathrm{dm}^{-3}$ ) was achieved at day 24 using the $2.5 \%$ alginate, while when using 2 and $1.5 \%$ alginate, the maximum production of the taxane was obtained at day $8\left(3.21 \mathrm{mg} \mathrm{dm}^{-3}\right)$ and day $24(2.22$ $\left.\mathrm{mg} \mathrm{dm}^{-3}\right)$, respectively. As indicated for free cultured cells, the capacity of the immobilized cultured cells to form paclitaxel and baccatin III decreased noticeably when the concentration of MJA was increased from 100 to $200 \mu \mathrm{M}$. The highest total paclitaxel content in presence of $200 \mu \mathrm{M}$ MJA $\left(5.16 \mathrm{mg} \mathrm{dm}^{-3}\right)$ was reached at day 24 when using $2 \%$ alginate. Compared to the highest content of the paclitaxel in presence of $100 \mu \mathrm{M}$ MJA $\left(13.20 \mathrm{mg} \mathrm{dm}^{-3}\right)$, this content was 2.5 -fold lower. Regarding the highest total baccatin III content of $3.82 \mathrm{mg} \mathrm{dm}^{-3}$, also reached at day 24 , but in this case using $2.5 \%$ alginate solution, this was only 1.2-fold lower than that of $4.62 \mathrm{mg} \mathrm{dm}^{-3}$ obtained in presence of $100 \mu \mathrm{M}$ MJA. It thus seems that the lower elicitor concentration promoted the accumu-lation of paclitaxel more strongly than that of baccatin III. The increase in the paclitaxel content in $100 \mu \mathrm{M}$ MJA-treated cultures of immobilized cells was considerably higher than in free cultured cells (see Fig. 1). However, in the case of baccatin III this increase was minimal.

On the other hand, as can be deduced from the excretion percentage values from day 8 to day 38 (Fig. 4), the accumulation of paclitaxel and baccatin III in the culture medium (i.e., their extracellular content), was clearly reduced by the cell entrapment in alginate, mainly

\section{References}

Bentebibel, S., Moyano, E., Palazón, J., Cusidó, R.M., Bonfill, M., Eibl, R., Piñol, M.T.: Effects of immobilization by entrapment in alginate and scale-up on paclitaxel and baccatin III in cell suspension cultures of Taxus baccata. Biotechnol. Bioeng. 89: 647-655, 2005.

Bonfill, M., Palazón, J., Cusidó, R.M., Joly, S., Morales, C., Piñol, M.T.: Influence of elicitors on taxane production and 3-hydroxy-3-methylglutaryl coenzyme A reductase activity in Taxus media cells. - Plant Physiol. Biochem. 41: 91-96, 2003.

Cusidó, R.M., Palazón, J., Bonfill, M., Navia-Osorio, A., Morales, C., Piñol, M.T.: Improved paclitaxel and baccatin III production in suspension cultures of Taxus media. - when the culture medium was supplemented with $100 \mu \mathrm{M}$ MJA. In this case, only an average of 2,4 and $3 \%$ of total paclitaxel and 31,18 and $8 \%$ of total baccatin III was released into the liquid medium during the culture of the beads prepared with 1.5, 2 and $2.5 \%$ alginate, respectively. However, when the culture medium was supplemented with $200 \mu \mathrm{M}$ MJA, an average of 45, 20 and $46 \%$ of total paclitaxel and 55, 26 and $65 \%$ of total baccatin III were released into the liquid medium during the culture of the beads prepared with 1.5, 2 and $2.5 \%$ alginate, respectively. The higher extracellular contents of both taxanes in presence of $200 \mu \mathrm{M}$ MJA were not a consequence of cell lysis, hence the viability percentage of entrapped cells $(>75 \%)$ was higher than that of those growing in presence of $100 \mu \mathrm{M}$ MJA (65 - $70 \%)$. However, from these data it can be deduced that this small viability reduction was related to the highest production level of paclitaxel in presence of $100 \mu \mathrm{M}$ MJA, rather than to the direct effect of methyl jasmonte. It has been reported that apoptotic cell death in suspension cultures of $T$. chinensis is closely related to paclitaxel accumulation (Yuan et al. 2002). This is supported by the observation that paclitaxel blocks mitosis at the transition between metaphase and anaphase by stabilizing the microtubules, which subsequently induces cell death (Jordon and Wilson 1995).

To sum up, using our methods and T. baccata cell line, we observed that immobilization encouraged production of both taxanes, yet very little was secreted. When comparing the highest concentrations of paclitaxel in elicited cultures with the greatest production observed in nonelicited cultures, it is evident that the most significant benefit of using MJA as an elicitor of paclitaxel was the increase in production rate, rather than its ultimate concentration in the medium. Although natural or artificially induced secretion of the accumulated product into the surrounding medium could be considered for the development of a more effective process (Bentebibel et al. 2005), the enrichment of paclitaxel in the alginate beads does not serve as a basis for its commercial production.

Biotechnol. Progr. 18: 418-423, 2002.

Cusidó, R.M., Palazón, J., Navia-Osorio, A., Mallol, A., Bonfill, M., Morales, C., Piñol, M.T.: Production of taxol and baccatin III by a selected Taxus baccata callus line and its derived cell suspension culture. - Plant Sci. 146: 101107, 1999.

Duncan, R.D., Widholm, J.M.: Measurements of viability suitable for plant tissue cultures. - In: Pollard, J.W., Walker, J.M. (ed.): Methods in Molecular Biology. Vol. 6. Pp. 2937. The Humana Press, Totowa 1990.

Fett-Neto, A.G., DiCosmo, F.: Taxol® and taxane production by cell culture. - In: Meyers, R.A. (ed.): Encyclopedia of Molecular Biology and Molecular Medicine. Vol. 6. Pp. 
10-17. VCH Verlags-Gesellschaft, Weinheim 1997.

Gamborg, O.L., Miller, R.A., Ojima. K.: Nutrient requirements of suspension cultures of soybean root cells. - Exp. Cell Res. 50: 151-158, 1968.

Gilleta, F., Roisin, C., Fliniaux, M.A., Jacquin-Dubreuil, A., Barbotin, J.N., Nava-Saucedo, J.E.: Immobilization of Nicotiana tabacum plant cell suspensions within calcium alginate gel beads for the production of enhanced amounts of scopolin. - Enzyme Microbiol. Technol. 26: 229-234, 2000.

Grothaus, P.G., Bignami, G.S., O’Malley, S., Harada, K.E., Byrnes, J.B., Walle, D.F., Raybould, T.J.G., MacGuire, M.T., Alvarado, B.: Taxane-specific monoclonal antibodies: measurement of taxol, baccatin III, and total taxanes in Taxus brevifolia extracts by enzyme immunoassay. - J. Natur. Prod. 58: 1003-1014, 1995.

Hall, R.D., Holden, M.A., Yeoman, M.M.: Immobilization of higher plant cells. - In: Bajaj, Y.P.S. (ed.): Biotechnology in Agriculture and Forestry. Vol. 4. Medicinal and Aromatic Plants I. Pp. 136-156. Springer-Verlag, Berlin 1988.

Hezari, M., Ketchum, R.E.B., Gibson, D.M., Croteau, R: Taxol production and taxadiene synthase activity in Taxus canadensis cell suspension cultures. - Arch. Biochem. Biophys. 337: 185-190, 1997.

Jordon, M.A., Wilson, L.: Microtubule polymerization dynamics, mitotic block, and cell death by paclitaxel at low concentrations. - In: Georg, G.I., Chen, T.T., Ojima, I., Vyas, D.M. (ed.): Taxane Anticancer Agents. Pp. 138-153. American Chemical Society, Washington 1995.

Ketchum, R.E.B., Gibson, D.M., Croteau, R.B., Shuler, M.L.: The kinetics of taxoid accumulation in cell suspension cultures of Taxus following elicitation with methyl jasmonate. - Biotechnol. Bioeng. 62: 97-105, 1999.

Ketchum, R.E.B., Rithner, C.D., Qiu, D., Kim, Y.S., Williams, R.M., Croteau, R.B.: Taxus metabolomics: methyl jasmonate preferentially induces production of taxoids oxygenated at C-13 in Taxus $\times$ media cell cultures. Phytochemistry 62: 901-909, 2003.
Koda, Y., Takahashi, K., Kikuta, Y., Greulich, F., Toshima, H., Ichihara, A.: Similarities of the biological activities of coronatine and coronafacic acid to those of jasmonic acid. Phytochemistry 41: 93-96, 1996.

Nicolaou, K.C., Yang, Z., Liu, J.J., Ueno, H., Nantermet, P.G., Guy, R.K., Claiborne, C.F., Renaud, J., Couladouros, E.A., Paulvannan, K., Sorensen, E.J.: Total synthesis of taxol. Nature 367: 630-634, 1994.

Palazón, J., Cusidó, R.M., Bonfill, M., Morales, C., Piñol, M.T.: Inhibition of paclitaxel and baccatin III accumulation by mevinolin and fosmidomycin in suspension cultures of Taxus baccata. - J. Biotechnol. 101: 157-163, 2003.

Seki, M., Ohzora, C., Takeda, M., Furusaki, S.: Taxol (paclitaxel) production using free and immobilized cells of Taxus cuspidata. - Biotechnol. Bioeng. 53: 214-219, 1997.

Srinivasan, V., Ciddi, V., Bring, V., Shuler, M.L.: Metabolic inhibitors, elicitors and precursors as tools for probing yield limitation in taxane production by Taxus chinensis cell cultures. - Biotechnol. Progr. 12: 457-465, 1996.

Tabata, H.: Paclitaxel production by plant-cell-culture technology. - Adv. Biochem. Eng. Biotechnol. 87: 1-23, 2004.

Villegas, M., León, R., Brodelius, P.E.: Effects of alginate and immobilization by entrapment in alginate on benzophenanthridine alkaloid production in cell suspension cultures of Eschscholtzia californica. - Biotechnol. Lett. 21: 49-55, 1999.

Yu, L.J., Lan, W.Z., Chen, C., Yang, Y., Sun, Y.P.: Importance of glucose-6-phosphate dehydrogenase in taxol biosynthesis in Taxus chinensis.- Biol. Plant. 49: 265-268, 2005.

Yuan, Y.J., Li, C., Hu, Z., Wu, J.C., Zeng, A.P.: Fungal elicitor-induced cell apoptosis in suspension cultures of Taxus chinensis var. mairei for taxol production. - Process Biochem. 38: 193-198, 2002.

Yukimune, Y., Tabata, H., Higashi, Y., Hara, Y.: Methyljasmonate-induced overproduction of paclitaxel and baccatin III in Taxus cell suspension cultures. - Nat. Biotechnol. 14: 1129-1132, 1996. 